\title{
New oral antithrombotics: focus on dabigatran, an oral, reversible direct thrombin inhibitor for the prevention and treatment of venous and arterial thromboembolic disorders
}

\author{
This article was published in the following Dove Press journal: \\ Vascular Health and Risk Management \\ 24 January 2012 \\ Number of times this article has been viewed
}

\author{
Ola E Dahl',2 \\ 'Department of Orthopaedics, \\ Innlandet Hospital Trust, Elverum \\ Central Hospital, Elverum, Norway; \\ ${ }^{2}$ Thrombosis Research Institute, \\ London, UK
}

\begin{abstract}
Venous thromboembolism, presenting as deep vein thrombosis or pulmonary embolism, is a major challenge for health care systems. It is the third most common vascular disease after coronary heart disease and stroke, and many hospitalized patients have at least one risk factor. In particular, patients undergoing hip or knee replacement are at risk, with an incidence of asymptomatic deep vein thrombosis of 40\%-60\% without thromboprophylaxis. Venous thromboembolism is associated with significant mortality and morbidity, with patients being at risk of recurrence, post-thrombotic syndrome, and chronic thromboembolic pulmonary hypertension. Arterial thromboembolism is even more frequent, and atrial fibrillation, the most common embolic source (cardiac arrhythmia), is associated with a five-fold increase in the risk of stroke. Strokes due to atrial fibrillation tend to be more severe and disabling and are more often fatal than strokes due to other causes. Currently, recommended management of both venous and arterial thromboembolism involves the use of anticoagulants such as coumarin and heparin derivatives. These agents are effective, although have characteristics that prevent them from providing optimal anticoagulation and convenience. Hence, new improved oral anticoagulants are being investigated. Dabigatran is a reversible, direct thrombin inhibitor, which is administered as dabigatran etexilate, the oral prodrug. Because it is the first new oral anticoagulant that has been licensed in many countries worldwide for thromboprophylaxis following orthopedic surgery and for stroke prevention in patients with atrial fibrillation, this compound will be the main focus of this review. Dabigatran has been investigated for the treatment of established venous thromboembolism and prevention of recurrence in patients undergoing hip or knee replacement, as well as for stroke prevention in atrial fibrillation patients with a moderate and high risk of stroke.
\end{abstract}

Keywords: dabigatran etexilate, venous thromboembolism, stroke, prevention, treatment

\section{Introduction}

This review will summarize the efficacy and safety data available for dabigatran etexilate (herein after referred to as dabigatran) as anticoagulation therapy for the prevention and treatment of venous thromboembolism and for stroke prevention in patients with atrial fibrillation. To provide a broader picture of this rapidly advancing area of therapy, we have included a brief overview of recent data on other new oral anticoagulants.

Two million people per year in the United States are affected by venous thromboembolism (deep vein thrombosis or pulmonary embolism), making venous
Correspondence: Ola E Dahl Innlandet Hospital Trust, Elverum Central Hospital, Kirkeveien, Elverum, Norway Tel +479093 6946; +44 792 II 22773

Email oladahl@start.no 
thromboembolism the third most common vascular disease after coronary heart disease and stroke. ${ }^{1}$ In Europe, the number of deaths resulting from venous thromboembolism is five times greater than the combined total deaths from breast cancer, acquired immune deficiency syndrome, and road traffic accidents. ${ }^{2}$

The consequences of developing venous thromboembolism are clinically important. Patients diagnosed with venous thromboembolism, especially pulmonary embolism, are at greater risk of death within the first 3 months than patients without venous thromboembolism, ${ }^{3}$ and patients with venous thromboembolism can develop long-term complications, such as post-thrombotic syndrome and chronic thromboembolic pulmonary hypertension. ${ }^{46}$ Furthermore, approximately $18 \%$ of patients will have recurrences of venous thromboembolism within 2 years, and one third of patients within 8 years. ${ }^{7}$

\section{Venous thromboembolism in orthopedic surgery}

Without thromboprophylaxis, major orthopedic surgery, such as total hip or knee replacement (THR or TKR), carries a risk of asymptomatic venous thromboembolism. This is because orthopedic surgery triggers a substantial local and systemic thrombin generation and activity, potentially leading to manifestation of thrombotic events on both the venous and arterial side. ${ }^{8,9}$ The relationship between asymptomatic and symptomatic venous thromboembolism has recently been demonstrated using data from prospective randomized trials, ie, one symptomatic venous thromboembolism developed for every five occurrences of asymptomatic deep vein thrombosis after THR, and for every 21 occurrences after TKR. ${ }^{10}$

Even if clinical events have decreased in recent years, ${ }^{11}$ rebound thrombin activity has been shown when prophylaxis with dalteparin was suspended at hospital discharge about one week post-surgery. ${ }^{9}$ Likely as a result of the early discontinuation of thromboprophylaxis, ${ }^{12}$ venous thromboembolism is the most common cause of readmission to hospital in patients who have undergone such surgery. ${ }^{13-15}$ In a study of patients who had undergone major hip and knee surgery with hospital-based thromboprophylaxis, most cases of venous thromboembolism developed after hospital discharge, confirming the need for continued thromboprophylaxis. The increased risk of venous thromboembolism was apparent for about 3 months after hip surgery and 1 month after knee surgery. ${ }^{11}$ Similarly, the increased absolute rate of deaths after THR (ie, in the same patient population between 100 and 200 days) was dominated by vascular events and lasted for about 3 months. ${ }^{11,16}$
In tandem with the increasing age of the population, the number of THR and TKR procedures is increasing in many countries, and this is likely to have a major impact on the number of patients experiencing postoperative systemic thromboembolic events. ${ }^{17-20}$

\section{Stroke in patients with atrial fibrillation}

Stroke is an arterial thromboembolic disease and a major complication of nonvalvular atrial fibrillation. ${ }^{21}$ Atrial fibrillation is the most common cardiac arrhythmia, affecting an estimated 4.5 million people in Europe and 2.3 million in the United States. ${ }^{22,23}$ Because the prevalence increases with age, it is predicted to increase significantly over the next 40 years as a result of the growing elderly population. ${ }^{22}$

According to age-adjusted rates from the Framingham Heart Study, patients with atrial fibrillation have a five-fold increase in risk for embolic stroke. ${ }^{21}$ It is estimated that atrial fibrillation may account for $45 \%$ of all embolic strokes and for $15 \%-20 \%$ of all strokes. ${ }^{24}$ Stroke due to atrial fibrillation tends to be particularly severe and disabling, and more likely to be fatal than strokes not due to atrial fibrillation. ${ }^{25,26}$ Patients with atrial fibrillation are at an increased risk of stroke because of the prothrombotic state that is associated with this condition, and this leads to a greater risk of thrombus formation. ${ }^{27-29}$ Without effective anticoagulation therapy, the average incidence of stroke in atrial fibrillation patients is 5\% per year. ${ }^{30}$ In addition to being associated with an increased risk of stroke, atrial fibrillation is associated with an increased risk of heart failure, death, and cognitive dysfunction, as well as a reduced quality of life. ${ }^{21,31-34}$

\section{Need for appropriate anticoagulation}

The need for effective anticoagulation therapy across multiple thromboembolic disease indications is clearly evident. A central and critical step in the coagulation cascade is the conversion of fibrinogen to fibrin, which is mediated by thrombin. Fundamental to hemostasis is the balance between fibrin deposition and removal, which protects the vascular system from blood loss at the site of an injury, whilst maintaining blood fluidity.

An objective of treatment with an anticoagulant agent is to optimize the balance between efficacy (prevention of thrombus formation) and safety (ie, bleeding and adverse events). For many years, coumarin derivatives (the vitamin $\mathrm{K}$ antagonists) have been the only oral agents available for long-term anticoagulation therapy. Although the 
vitamin $\mathrm{K}$ antagonists are effective, their use is limited by their slow onset and offset of action, narrow therapeutic window, multiple drug and food interactions, unpredictable anticoagulant effect (which may cause severe bleeding), and requirement for regular anticoagulant monitoring and dose adjustment. ${ }^{35}$ Patients not maintained within the therapeutic window remain at risk of thromboembolism (under-anticoagulated) or have an increased risk of bleeding (over-anticoagulated). ${ }^{36}$

The heparin derivatives, although differing in their side effect profiles, as a class have their main drawback in long-term use, since they are only available as injectable compounds. Such limitations to providing optimal anticoagulation have motivated the search for improved oral anticoagulants.

Direct thrombin inhibition has been established as an effective approach to anticoagulation therapy because of the central role that thrombin plays in thrombus formation during hemostasis, thrombosis, and inflammation. Dabigatran is the first available oral direct thrombin inhibitor approved for marketing for the prevention of venous thromboembolism following orthopedic surgery and for prevention of arterial embolism and stroke in patients with atrial fibrillation. It is currently under investigation for the prevention and treatment of other types of venous and arterial thrombosis. ${ }^{37,38}$ Dabigatran offers potential advantages over currently available anticoagulants because it is administered orally and its predictable anticoagulant effect abrogates the need for coagulation monitoring. After major orthopedic surgery it has favorable, slow postoperative onset with delayed absorption and a reduced plasma peak concentration that does not tend to disturb the ongoing hemostatic process. This contrasts with a rapid onset of action in nonsurgical patients where such an effect is wanted. ${ }^{39-41}$

\section{Dabigatran for prevention of venous thromboembolism post orthopedic surgery}

Effective anticoagulation reduces the risk of developing venous thromboembolism following orthopedic surgery and is recommended in evidence-based guidelines. ${ }^{42}$ Based on the efficacy and safety data from a number of pivotal trials with enoxaparin $40 \mathrm{mg}$ once daily as comparator, dabigatran was initially approved by Health Canada and the European Medicines Agency in 2008 for use in the prevention of venous thromboembolism following THR and TKR surgery and is now available in more than 75 countries. The results from trials in elective major joint surgery showed that dabigatran (150 mg and $220 \mathrm{mg}$ once daily) has similar efficacy compared with the low molecular weight heparin, enoxaparin (40 mg once daily, initiated preoperatively) in adults with normal renal function. ${ }^{43,44}$ In patients with reduced kidney function and the elderly, regulatory authorities have recommended the lower dabigatran dose $(150 \mathrm{mg})$ to avoid drug accumulation and risk of bleeding complications. ${ }^{45}$

In the RE-MODEL ${ }^{\mathrm{TM}}$ trial in patients undergoing TKR, the primary efficacy outcome, the composite of total venous thromboembolism and mortality, occurred in 37.7\% (193/512) of the enoxaparin group compared with $36.4 \%(183 / 503)$ of the dabigatran $220 \mathrm{mg}$ group and 40.5\% (213/526) of the dabigatran $150 \mathrm{mg}$ group. ${ }^{44}$ In this trial, both doses of dabigatran were noninferior to enoxaparin on the basis of prespecified noninferiority criteria. In addition, rates of the secondary efficacy outcome, major venous thromboembolism and venous thromboembolism-related mortality, were also similar (3.5\% for enoxaparin and $2.6 \%$ and $3.8 \%$ for dabigatran $220 \mathrm{mg}$ and $150 \mathrm{mg}$, respectively). ${ }^{44}$

In the RE-NOVATE ${ }^{\circledR}$ I trial in THR, the primary efficacy outcome occurred in $6.7 \%(60 / 897)$ of the enoxaparin group compared with $6.0 \%$ (53/880) of the dabigatran $220 \mathrm{mg}$ group and $8.6 \%$ (75/874) of the dabigatran $150 \mathrm{mg}$ group. ${ }^{43}$ As in the RE-MODEL trial, both doses of dabigatran were noninferior to enoxaparin, and rates of major venous thromboembolism and venous thromboembolism-related mortality were also similar (3.9\% for enoxaparin and $3.1 \%$ and $4.3 \%$ for dabigatran $220 \mathrm{mg}$ and $150 \mathrm{mg}$, respectively). ${ }^{43}$

A more recent trial in total hip replacement, RE-NOVATE II, confirmed the noninferiority of dabigatran $220 \mathrm{mg}$. The primary efficacy outcome occurred in $8.8 \%$ (69/785) of the enoxaparin group compared with $7.7 \%$ (61/792) of the dabigatran group. Moreover, dabigatran was superior to enoxaparin for the clinically relevant endpoint of major venous thromboembolism and venous thromboembolismrelated death $(4.2 \%$ for enoxaparin and $2.2 \%$ for dabigatran $220 \mathrm{mg}){ }^{46}$ Similar results for the more clinically relevant endpoint were also supported by a pooled analysis of RE-MODEL, RE-NOVATE I, and RE-MOBILIZE ${ }^{\circledR 47}$ (the latter trial compared dabigatran with a postoperative regimen of enoxaparin $30 \mathrm{mg}$ twice daily [as used in the United States]). ${ }^{48}$

In terms of safety, all of these trials showed similar perioperative bleeding rates to enoxaparin $40 \mathrm{mg}$ once daily (Table 1). In the RE-MODEL trial, major bleeding events (including surgical site bleeds from preoperative baseline) occurred in $1.3 \%$ of the enoxaparin group compared with $1.5 \%$ of the dabigatran $220 \mathrm{mg}$ group and $1.3 \%$ of the 
Table I Rates of bleeding in clinical trials comparing dabigatran with enoxaparin $40 \mathrm{mg}$ once daily for primary prevention of venous thromboembolism ${ }^{43,44,46}$

\begin{tabular}{|c|c|c|c|}
\hline & $\begin{array}{l}\text { Dabigatran } 220 \mathrm{mg} \\
\text { once daily }\end{array}$ & $\begin{array}{l}\text { Dabigatran } 150 \mathrm{mg} \\
\text { once daily }\end{array}$ & $\begin{array}{l}\text { Enoxaparin } 40 \mathrm{mg} \\
\text { once daily }\end{array}$ \\
\hline \multicolumn{4}{|l|}{ RE-NOVATE ${ }^{\circledR}$ I trial } \\
\hline Major bleeding, \% ${ }^{a}$ & 2.0 & 1.3 & 1.6 \\
\hline Major bleeding plus clinically relevant nonmajor bleeding, \% & 6.2 & 6.0 & 5.0 \\
\hline \multicolumn{4}{|l|}{ RE-NOVATE ${ }^{\circledR}$ II trial } \\
\hline Major bleeding, \% & 1.4 & - & 0.9 \\
\hline Major bleeding plus clinically relevant nonmajor bleeding, \% & 3.7 & - & 2.9 \\
\hline \multicolumn{4}{|l|}{ RE-MODEL ${ }^{\mathrm{TM}}$ trial } \\
\hline Major bleeding, \% & 1.5 & 1.3 & 1.3 \\
\hline Major bleeding plus clinically relevant nonmajor bleeding, \% & 7.4 & 8.1 & 6.6 \\
\hline
\end{tabular}

Notes: ${ }^{a}$ One fatal bleeding event in each dabigatran group, no bleeding into critical organs; ${ }^{b}$ no fatal bleeding, one critical organ bleed in the dabigatran 150 mg group. Major bleeding during the treatment period was defined as clinically overt bleeding associated with $\geq 20$ g/L fall in hemoglobin; clinically overt leading to transfusion of $\geq 2$ units packed cells or whole blood; fatal, retroperitoneal, intracranial, intraocular, or intraspinal bleeding; bleeding warranting treatment cessation or leading to reoperation. Clinically relevant nonmajor bleeding events were defined as spontaneous skin hematoma $\geq 25 \mathrm{~cm}^{2}$; wound hematoma $\geq 100 \mathrm{~cm}$; epistaxis $>5$ minutes; spontaneous macroscopic hematuria or that lasting $>24$ hours if associated with an intervention; spontaneous rectal bleeding; gingival bleeding $>5$ minutes; or any other bleeding event judged as clinically significant by the investigator.

dabigatran $150 \mathrm{mg}$ group. ${ }^{44}$ In the RE-NOVATE I trial, major bleeding occurred in $1.6 \%$ of the enoxaparin group compared with $2.0 \%$ of the dabigatran $220 \mathrm{mg}$ group and $1.3 \%$ of the dabigatran $150 \mathrm{mg}$ group..$^{43}$ In RE-NOVATE II, major bleeding occurred in $0.9 \%$ of the enoxaparin group compared with $1.4 \%$ of the dabigatran $220 \mathrm{mg}$ group. ${ }^{46}$ Data for the composite of major and clinically relevant bleeding events are also given in Table 1, and bleeding definitions are given in the footnote to the Table.

Many patients undergoing THR or TKR are at increased risk of bleeding because of older age and potential reduction in renal function, which also decreases with age. A pooled analysis from the RE-MODEL and RE-NOVATE I trials showed that in patients older than 75 years and in those with moderate renal impairment, dabigatran $150 \mathrm{mg}$ once daily was as effective as enoxaparin but with significantly less bleeding. ${ }^{49}$

Dabigatran (220 mg and $150 \mathrm{mg}$ once daily) is approved in many countries for use in the prevention of venous thromboembolism in patients undergoing hip or knee replacement surgery. The $220 \mathrm{mg}$ once daily dose is recommended for the majority of patients, while the $150 \mathrm{mg}$ once daily dose is recommended for patients older than 75 years, with moderate renal impairment, or taking concomitant verapamil, quinidine, or amiodarone. Treatment can be initiated within 1-4 hours of surgery with a half dose and continued from the following day with the full dose. ${ }^{45}$ Or, if preferred, low molecular weight heparin can be injected and switched to dabigatran at any postoperative day. Because no data are available, it is not recommended to start the administration of dabigatran until the next dose of parenteral anticoagulant would have been due. ${ }^{45}$
In summary, dabigatran is an effective oral anticoagulation therapy for venous thromboembolism prevention following major joint replacement surgery. Clinical trials have shown that dabigatran offers thromboprophylaxis comparable with enoxaparin $40 \mathrm{mg}$ once daily with a similar or improved safety profile following hip or knee replacement surgery. Dabigatran can be conveniently administered, and a lower dose (150 mg once daily) is available for older patients and those with moderate renal impairment or taking strong P-glycoprotein inhibitors, as supported by the assessment of the European Medicines Agency for dabigatran. ${ }^{50}$ Similarly, the European Medicines Agency has recently recommended the use of a lower dose of fondaparinux (1.5 $\mathrm{mg}$ rather than $2.5 \mathrm{mg}$ ) in elderly patients as a result of evidence on bleeding events from postmarketing reports. ${ }^{51}$

\section{Other new anticoagulants}

Another novel oral anticoagulant agent licensed for venous thromboembolism prevention following orthopedic surgery is rivaroxaban, which is a direct factor Xa inhibitor. ${ }^{52}$ Rivaroxaban was started 6-8 hours after surgery and compared with enoxaparin $40 \mathrm{mg}$ once daily started 12 hours before surgery in three trials, ie, RECORD 1, 2, and 3,,$^{53-55}$ and with enoxaparin $30 \mathrm{mg}$ twice daily started 12-24 hours after surgery in one trial (RECORD 4). ${ }^{52}$ Only one dose of rivaroxaban is licensed. It appears to be safe and convenient, but concerns have been raised over the potential for increased bleeding and wound complications. ${ }^{56-62}$ The study investigators cite differences in the definition of major bleeding and statistical methodology as possible reasons for the different interpretations of bleeding data from the rivaroxaban program. ${ }^{61}$ To investigate this further, a meta-analysis of pivotal studies 
comparing dabigatran with enoxaparin or rivaroxaban with enoxaparin for venous thromboembolism prevention after THR or TKR was undertaken using bleeding rates relative to those caused by the same dose of enoxaparin for each compound. Because no standardized bleeding definitions exist and no head-to-head studies have been conducted, it is not possible to perform direct comparisons of dabigatran and rivaroxaban. This analysis demonstrated that dabigatran shows similar rates of efficacy and bleeding to enoxaparin, while rivaroxaban is more effective than enoxaparin but has a significantly higher risk of bleeding. ${ }^{58,63}$ Recently, a significantly increased rate of wound-related complications was reported by an orthopedic group based in the United Kingdom. ${ }^{59}$ Whether this increased risk of bleeding and related complications is due to the dose being too high, the timing of the first dose, or other aspects related to its pharmacology, needs to be addressed in further studies..$^{56,57,64}$ The US Food and Drug Administration has requested a lower-dose rivaroxaban tablet $(5 \mathrm{mg}$ ) to be developed to allow dose titration in populations at risk of increased drug exposure. ${ }^{65}$

Two trials have compared apixaban $2.5 \mathrm{mg}$ twice daily started 12-24 hours after surgery with enoxaparin $40 \mathrm{mg}$ once daily subcutaneously started 12 hours preoperatively. The ADVANCE- 2 and ADVANCE-3 trials in TKR and THR surgery demonstrated that apixaban is more effective than the enoxaparin regimen for the primary efficacy outcome (asymptomatic and symptomatic deep vein thrombosis, nonfatal pulmonary embolism, and all-cause death), with no significant difference in the rate of major or clinically relevant bleeding (as specified in the trial) between the two treatments. ${ }^{66,67}$ The late initiation of the compound in this regimen is more similar to the United States treatment protocol, where late postoperative initiation of enoxaparin has been practiced. A comparison with the United States enoxaparin regimen (30 mg twice daily subcutaneously initiated 12-24 hours after surgery) in TKR was made in the ADVANCE-1 trial. It did not meet the noninferiority efficacy criteria but showed some slightly lower bleeding parameters. ${ }^{68}$

Any direct comparisons of results between recent trials are impossible because of a variety of study-specific bleeding definitions and the lack of international endpoint standardization and standard operating procedures. ${ }^{69,70}$ Only postmarketing reports will establish the benefits and drawbacks of the new compounds in nonselected patients. The compounds will also show their robustness in daily practice and when hospital drug application routines may deviate from the recommended application schedules.

\section{Dabigatran in acute venous thromboembolism}

The goals of anticoagulant treatment in venous thromboembolism are to prevent the thrombus from increasing in size and embolizing, to prevent recurrence of deep vein thrombosis and pulmonary embolism, and to reduce the occurrence of long-term complications. ${ }^{71}$ Current treatment guidelines recommend a rapidly acting parenteral heparin derivative for 5-7 days with overlapping treatment using a vitamin $\mathrm{K}$ antagonist that is continued for at least 3 months, depending on the underlying cause and presence of risk factors. ${ }^{72}$

Recent results from the RE-COVER ${ }^{\mathrm{TM}}$ trial, a randomized, double-blind, noninferiority trial, show that dabigatran is as effective as warfarin for the treatment of acute venous thromboembolism. The study included 2564 patients who had acute, symptomatic, objectively verified proximal deep vein thrombosis of the legs or pulmonary embolism, in whom 6 months of anticoagulation therapy was considered appropriate. Patients were initially treated with parenteral anticoagulation therapy (low molecular weight heparin, unfractionated heparin, or fondaparinux) for at least 5 days and until international normalized ratio (INR) or sham INR exceeded 2.0, followed by 6 months of therapy with either $150 \mathrm{mg}$ dabigatran twice daily or warfarin (target INR 2.0-3.0). ${ }^{73}$ This strategy was chosen to protect patient safety by using the accepted gold standard therapy during the first few days when patients are most at risk. A previous study showed that ximelagatran, when administered without initial parenteral therapy in acute venous thromboembolism, is associated with a higher early rate of recurrent venous thromboembolism than enoxaparin followed by warfarin. ${ }^{74}$

In the RE-COVER trial, the primary efficacy outcome (6-month incidence of recurrent symptomatic, objectively confirmed venous thromboembolism and venous thromboembolism-related deaths) occurred in 2.4\% (30/1274) of the dabigatran $150 \mathrm{mg}$ twice daily group compared with $2.1 \%(27 / 1265)$ of the warfarin group $(P<0.001$ for noninferiority, Figure 1A). ${ }^{73}$ While rates of major bleeding were similar, $1.6 \%$ in the dabigatran group compared with $1.9 \%$ in the warfarin group (hazard ratio with dabigatran at 6 months $0.82 ; 95 \%$ confidence interval [CI] 0.45-1.48; $P=0.38$ ), major or clinically relevant nonmajor bleeding was significantly lower with dabigatran $(5.6 \%)$ than warfarin (8.8\%; hazard ratio at 6 months: 0.63 ; 95\% CI $0.47-0.84$; $P=0.002$ ). Episodes of any bleeding occurred in $16.1 \%$ of the dabigatran group compared with $21.9 \%$ of the warfarin group (hazard ratio at 6 months: 0.71 ; 95\% CI 0.59-0.85; $P<0.001$, Figure 1B). There were no cases of intracranial 
A

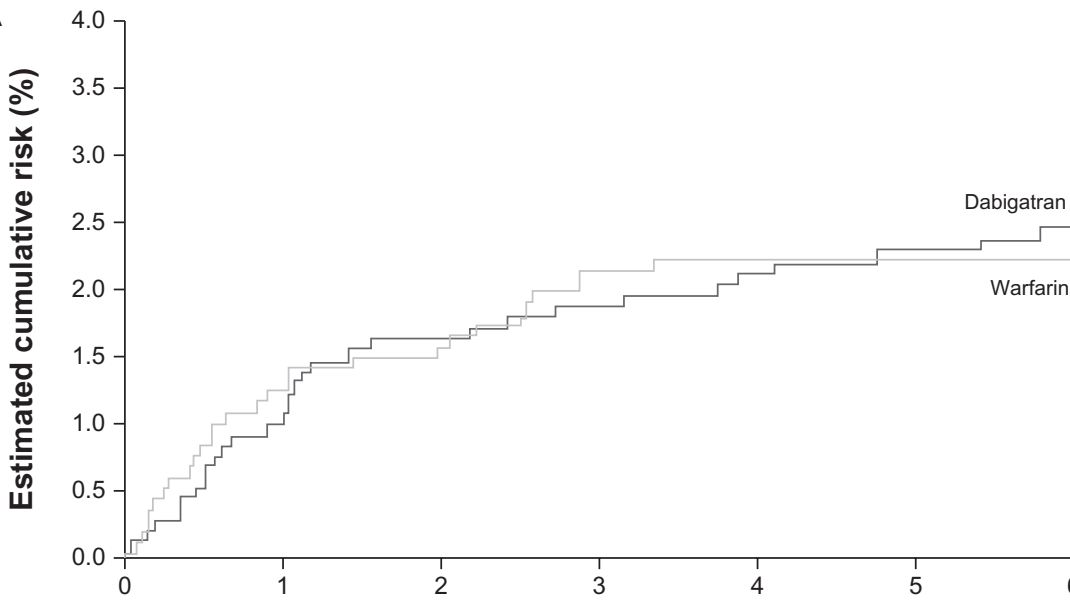

Months since randomization

$\begin{array}{llllllll}\text { Number at risk } & & & & & 1192 & 1181 & 1024 \\ \text { Dabigatran } & 1274 & 1238 & 1221 & 1203 & 1192 & 998 \\ \text { Warfarin } & 1265 & 1215 & 1204 & 1194 & 1187 & 1174 & \end{array}$

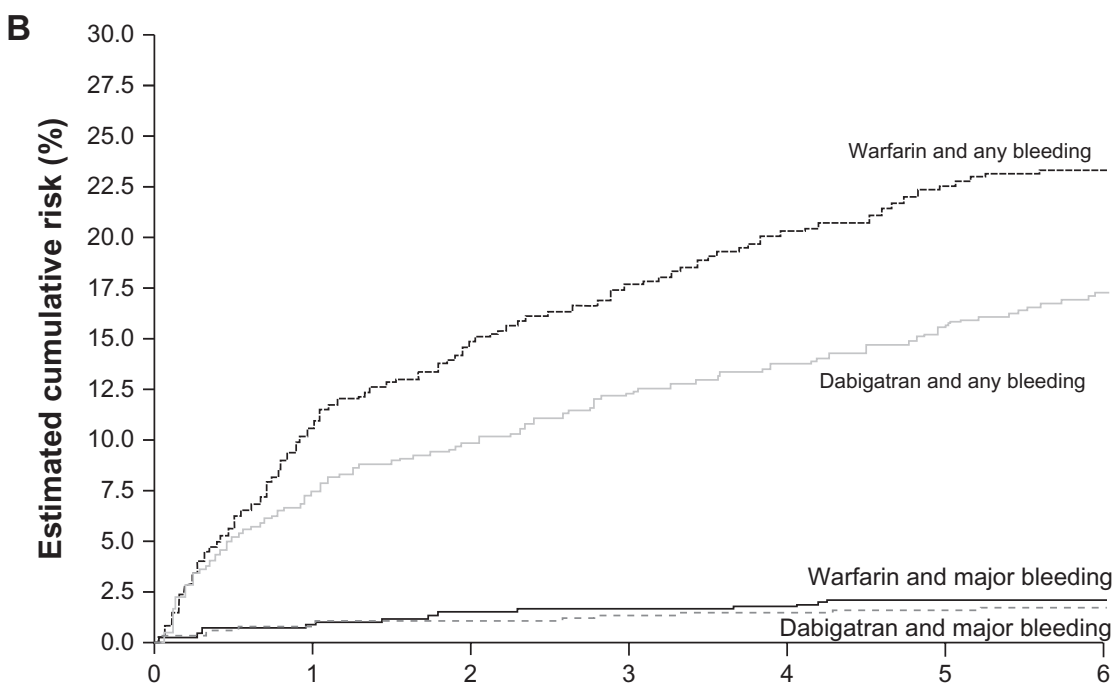

Months since first intake of study drug

$\begin{array}{lccccccc}\begin{array}{l}\text { Number at risk } \\ \text { Dabigatran and } \\ \text { major bleeding }\end{array} & 1273 & 1194 & 1153 & 1124 & 1105 & 1080 & 884 \\ \begin{array}{l}\text { Warfarin and } \\ \text { major bleeding }\end{array} & 1266 & 1178 & 1146 & 1128 & 1110 & 1093 & 859 \\ \begin{array}{l}\text { Dabigatran and } \\ \text { any bleeding }\end{array} & 1273 & 1117 & 1055 & 1002 & 971 & 931 & 747 \\ \begin{array}{l}\text { Warfarin and } \\ \text { any bleeding }\end{array} & 1266 & 1064 & 993 & 950 & 909 & 870 & 692\end{array}$

Figure I Incidence of (A) combined confirmed venous thromboembolism and venous thromboembolism death, and (B) any bleeding in the RE-COVER ${ }^{\mathrm{TM}}$ trial. (Schulman S, et al. N Engl J Med. 2009;36I (24):2342-2352, ${ }^{73}$ with permission from the Massachusetts Medical Society).

hemorrhage in the dabigatran group, compared with three in the warfarin group. ${ }^{73}$

In summary, the results of the RE-COVER trial support the use of dabigatran as an oral fixed-dose anticoagulant for the long-term treatment of acute venous thromboembolism. Dabigatran was as effective as dose-adjusted warfarin with a significantly lower rate of major or clinically relevant bleeds, and of any bleeding. ${ }^{73}$ In addition, the pharmacologic characteristics of dabigatran mean that it is likely to be more convenient to use than dose-adjusted warfarin in the real-world setting. ${ }^{73}$ Switching from low molecular weight heparin to dabigatran, as in the treatment of venous 
thromboembolism after initial treatment with an injectable agent, is straightforward; dabigatran is administered at the time of the next scheduled dose of parenteral anticoagulant. ${ }^{45}$ A second study of dabigatran for the treatment of acute venous thromboembolism, RE-COVER II, is underway and expected to be complete in 2011.

Studies are also investigating the efficacy and safety of dabigatran for the secondary prevention of venous thromboembolism compared with placebo and warfarin (RE-MEDY $^{\mathrm{TM}}$ and RE-SONATE ${ }^{\mathrm{TM}}$ ). The RE-MEDY trial compares dabigatran (150 mg twice daily) with dose-adjusted warfarin (INR of 2.0-3.0) for the secondary prevention of venous thromboembolism in 2700 patients who have been successfully treated with an anticoagulant for 3-12 months for confirmed acute symptomatic venous thromboembolism. Treatment duration is up to 36 months and the primary efficacy outcome is the composite incidence of recurrent symptomatic deep vein thrombosis/pulmonary embolism and venous thromboembolism-related death, which have been objectively confirmed by a definitive diagnostic evaluation. ${ }^{75}$ The RE-SONATE trial includes approximately 1800 patients with symptomatic deep vein thrombosis or pulmonary embolism who have completed 6-18 months of treatment with a vitamin $\mathrm{K}$ antagonist. These patients are to be randomized to double-blind dabigatran (150 mg twice daily) or placebo for 6 months. The primary efficacy outcome is the 6-month incidence of recurrent symptomatic, objectively confirmed venous thromboembolism. ${ }^{76}$

\section{Other new anticoagulants}

Two Phase III studies of rivaroxaban in venous thromboembolism treatment or secondary prevention have been completed. EINSTEIN-DVT was an open-label trial of 3449 patients with acute symptomatic deep vein thrombosis randomized to rivaroxaban (15 mg twice daily for 3 weeks, then $20 \mathrm{mg}$ once daily) or to enoxaparin followed by a vitamin $\mathrm{K}$ antagonist for up to 12 months. Rivaroxaban was noninferior for prevention of recurrent venous thromboembolism $(2.1 \%$ versus $3.0 \%$ with enoxaparin/vitamin $\mathrm{K}$ antagonist), while the rates of the composite of major and clinically relevant nonmajor bleeding were similar between groups $(8.1 \%$ each $) .{ }^{77} \mathrm{In}$ the double-blind EINSTEIN-Extension trial, 1196 patients who had undergone 6-12 months of treatment for venous thromboembolism were assigned to rivaroxaban $20 \mathrm{mg}$ once daily or placebo for an additional 6-12 months. Rivaroxaban was superior for efficacy (1.3\% versus $7.1 \%)$ and statistically similar to placebo for major bleeding $(0.7 \%$ versus $0 \%$, respectively; $P=0.11$ ). The composite of first major and clinically relevant nonmajor bleeding events was more frequent with rivaroxaban than with placebo $(6.0 \%$ versus $1.2 \%$; hazard ratio $5.19 ; 95 \%$ CI $2.3-11.7 ; P<0.001) .{ }^{77}$

\section{Dabigatran for stroke prevention in atrial fibrillation}

Current guidelines for the prevention of stroke and other thromboembolic complications in patients with atrial fibrillation recommend treatment with a vitamin $\mathrm{K}$ antagonist (eg, warfarin) or aspirin depending on the level of stroke risk. ${ }^{23,30,69,70,78-80}$ The most recent guidelines from The Canadian Cardiovascular Society and the American College of Cardiology Foundation/American Heart Association/Heart Rhythm Society include recommendations for dabigatran as an alternative, and potentially a preferred alternative, to warfarin. ${ }^{78,80}$ As already discussed, conventional therapies have many limitations, and in particular central nervous system bleeding in patients taking vitamin $\mathrm{K}$ antagonists is a feared complication, so there is a clear clinical need for new safe oral anticoagulant agents.

The RE-LY ${ }^{\circledR}$ trial was a Phase III, multicenter, prospective, randomized, open-label, blinded, endpoint-adjudication trial in 18,113 patients with nonvalvular atrial fibrillation and at least one risk factor for stroke. ${ }^{81}$ Treatment with dabigatran (150 mg twice daily) was associated with a significantly lower rate of stroke and systemic embolism than warfarin $(1.11 \%$ per year versus $1.71 \%$ per year; relative risk $0.65 ; 95 \% \mathrm{CI}$ $0.52-0.81 ; P<0.001$ for superiority, Figure 2). ${ }^{81,82}$ The rate of stroke and systemic embolism was $1.54 \%$ in the dabigatran $110 \mathrm{mg}$ twice daily group (relative risk $0.90 ; P<0.001$ for noninferiority; $P=0.30$ for superiority). Dabigatran $150 \mathrm{mg}$ twice daily was associated with a longer time to first stroke or systemic embolism than warfarin (relative risk reduction of $35 \%) .{ }^{81}$ Both doses of dabigatran had significantly lower rates of hemorrhagic stroke than dose-adjusted warfarin (dabigatran $110 \mathrm{mg}$ : $0.12 \%$ per year, $P<0.001$ for superiority; dabigatran $150 \mathrm{mg}$ : $0.10 \%, P<0.001$ for superiority; warfarin: $0.38 \%$ per year). In terms of vascular mortality, treatment with doseadjusted warfarin was associated with a rate of $2.69 \%$ per year compared with $2.43 \%$ per year for dabigatran $110 \mathrm{mg}(P=0.21$ for superiority) and $2.28 \%$ per year for dabigatran $150 \mathrm{mg}$ $\left(P=0.04\right.$ for superiority versus warfarin).$^{81,82}$ A prespecified subgroup analysis of the RE-LY trial demonstrated that the benefit of dabigatran compared with dose-adjusted warfarin was maintained whether patients were vitamin $\mathrm{K}$ antagonistnaïve or -experienced prior to entering the study. ${ }^{83}$

Furthermore, both dabigatran doses showed a significant reduction in intracranial hemorrhage compared with 


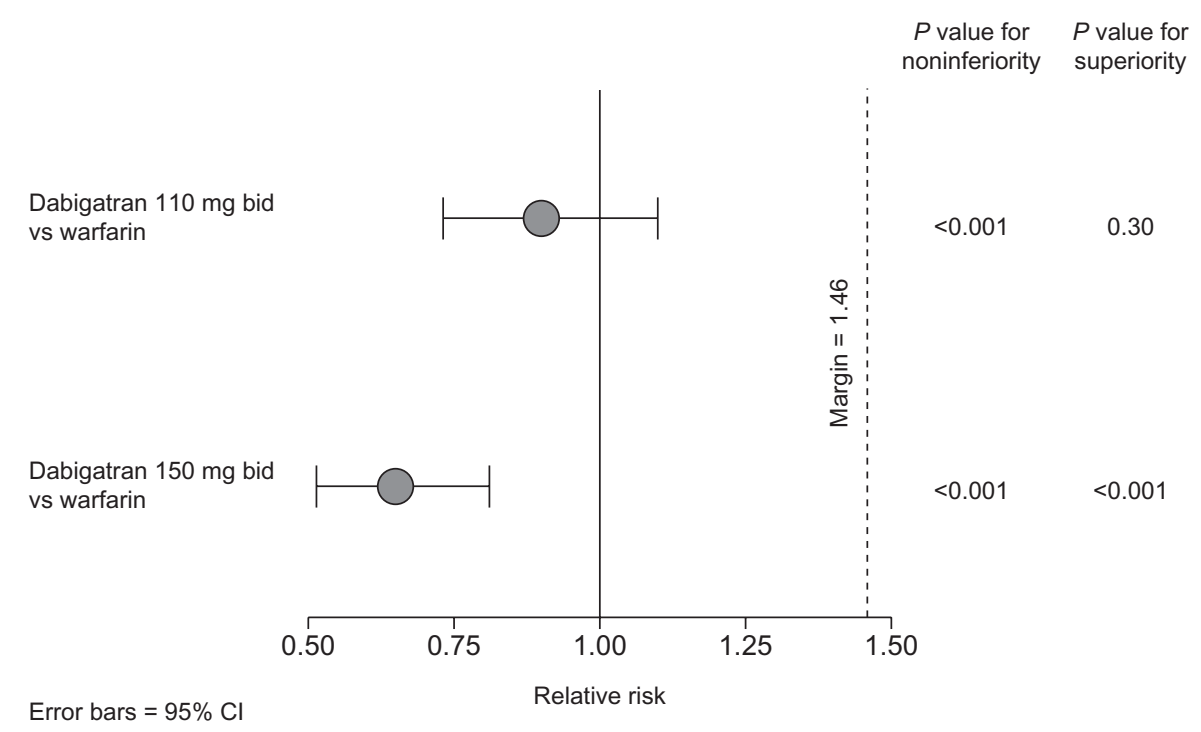

Figure 2 Combined risk of stroke and systemic embolism relative to warfarin in the RE-LY ${ }^{\circledR}$ trial. ${ }^{81,82}$

dose-adjusted warfarin (Figure 3). Dabigatran was also associated with significantly lower rates of life-threatening bleeding (relative risk 0.67 for dabigatran $110 \mathrm{mg}$ and 0.80 for $150 \mathrm{mg}$ ), and total bleeding (relative risk 0.78 for dabigatran $110 \mathrm{mg}$ and 0.91 for $150 \mathrm{mg}$ ). Treatment with dabigatran $150 \mathrm{mg}$ twice daily was associated with a similar rate of major bleeding compared with warfarin (3.32\% per year versus $3.57 \%$ per year; $P=0.31$ ), while dabigatran $110 \mathrm{mg}$ twice daily was associated with a significantly lower major bleeding rate (2.87\% versus $3.57 \%$ per year; $P=0.003){ }^{81,82}$

Dabigatran has not been evaluated for the initial treatment of stroke in patients with atrial fibrillation. However, about
$20 \%$ of patients in RE-LY had a previous stroke or transient ischemic attack before entering the study, and dabigatran was effective for secondary prevention in these patients. A subgroup analysis showed that the effects of dabigatran in patients who had a previous stroke or transient ischemic attack before entering RE-LY were consistent with those of other patients in the study. ${ }^{84}$

In summary, dabigatran $110 \mathrm{mg}$ twice daily shows similar efficacy to warfarin for stroke prevention in patients with atrial fibrillation but with significantly lower rates of major bleeding. Dabigatran $150 \mathrm{mg}$ twice daily is significantly more effective than warfarin and associated with similar rates of major

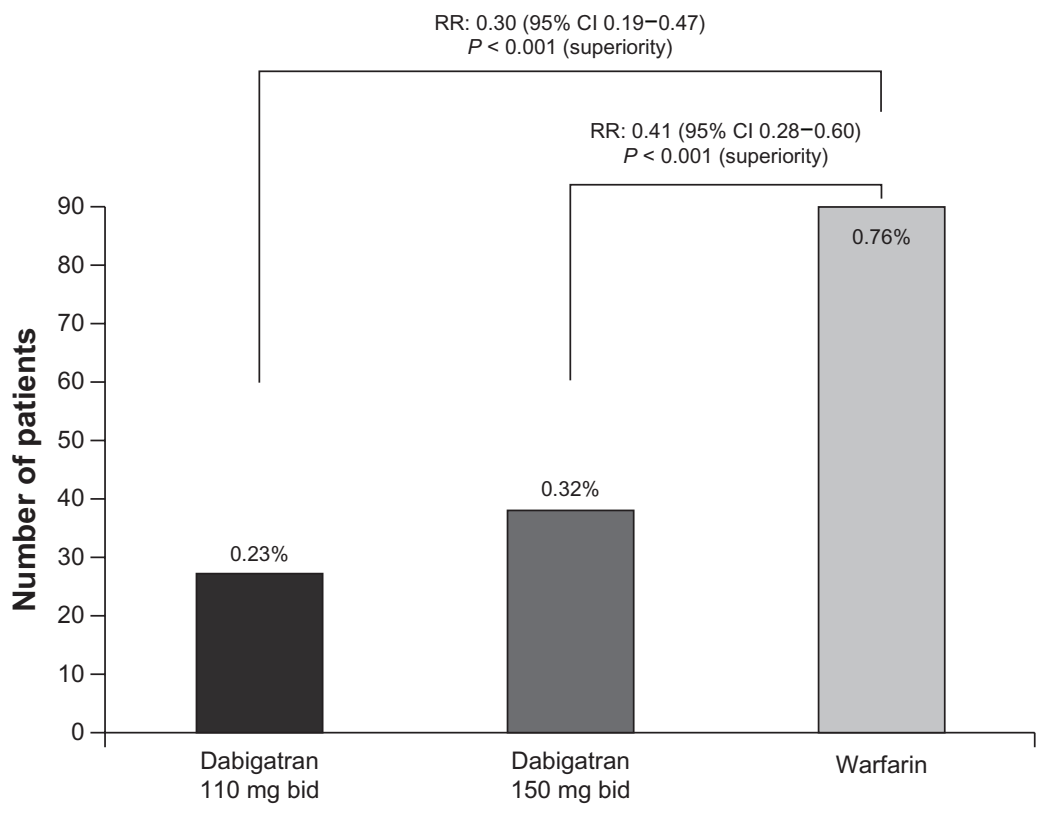

Figure 3 Rate of intracranial hemorrhage with dabigatran vs warfarin in the RE-LY ${ }^{\circledast}$ trial..$^{81,82}$ 
bleeding. Significant reductions in the risks of hemorrhagic stroke, intracranial hemorrhage, and total bleeding events were seen with both doses of dabigatran..$^{81,85}$

Dabigatran has been approved for stroke prevention in patients with atrial fibrillation in the United States, Canada, and the European Union at a usual dose of $150 \mathrm{mg}$ twice daily. In the United States, the recommended dose for patients with severe renal impairment is $75 \mathrm{mg}$ twice daily. ${ }^{86}$ In Canada and Europe, the dose recommended for patients $\geq 80$ years of age or at higher risk of bleeding is $110 \mathrm{mg}$ twice daily. ${ }^{87}$

\section{Other new anticoagulants}

The results of the ROCKET-AF trial of rivaroxaban $20 \mathrm{mg}$ once daily versus warfarin for stroke prevention have been presented. Patients included in this trial had a higher stroke risk than those in RE-LY, ie, either a prior stroke, transient ischemic attack, or systemic embolism, or at least two other stroke risk factors. Rivaroxaban was shown to be noninferior to warfarin for prevention of stroke or systemic embolism (1.71\% per year versus $2.16 \%$ per year, respectively). However, it was not superior to warfarin in the conventional intention-to-treat analysis (although it achieved statistical superiority in an on-treatment analysis). Rates of major bleeding (3.60\% per year versus 3.45\% per year, respectively) and nonmajor clinically relevant bleeding ( $11.80 \%$ per year versus $11.37 \%$ per year, respectively) were similar between treatments, while intracranial hemorrhage was reduced with rivaroxaban $(0.49 \%$ per year versus $0.74 \%$ per year, respectively; $P=0.019) .{ }^{88}$

The AVERROES trial compared apixaban $5 \mathrm{mg}$ twice daily with aspirin in patients with atrial fibrillation who were at increased risk for stroke and for whom vitamin $\mathrm{K}$ antagonist therapy was deemed to be unsuitable. Apixaban was superior to aspirin for prevention of stroke or systemic embolism (1.6\% per year versus 3.7\% per year, respectively) with similar rates of major bleeding $(1.4 \%$ per year versus $1.2 \%$ per year) and similar rates of intracranial hemorrhage (11 versus 13 events). ${ }^{89}$

The ARISTOTLE trial included patients with atrial fibrillation and at least one additional risk factor for stroke. Patients in the apixaban $5 \mathrm{mg}$ twice daily group had fewer stroke or systemic embolic events compared with patients taking warfarin (1.27\% per year versus $1.6 \%$ per year, respectively). Lower rates of major bleeding ([apixaban] 2.13\% per year versus [warfarin] $3.09 \%$ per year) and intracranial hemorrhage $(0.33 \%$ per year versus $0.80 \%$ per year, respectively) were also reported..$^{90}$
Interestingly, the ARISTOTLE results also showed a decreased overall mortality in patients treated with apixaban as compared with warfarin $(3.52 \%$ per year versus $3.94 \%$ per year; $P=0.047$ ). The RE-LY trial also showed almost the same decreased overall mortality with dabigatran $150 \mathrm{mg}$ twice daily compared with warfarin $(3.6 \%$ per year versus $4.13 \%$ per year; $P=0.051$ ) although this did not reach the formal predefined statistical significance. This could be due to the statistical power of the trials. Furthermore, dabigatran $150 \mathrm{mg}$ twice daily demonstrated a statistically significant reduction in ischemic stroke (the predominant type of stroke associated with atrial fibrillation) compared with warfarin, but the reduction in ischemic stroke did not reach statistical significance with apixaban versus warfarin. More studies are required to understand fully the relative merits of these new agents.

\section{Safety profile of dabigatran}

Hepatic safety has been carefully investigated in all clinical trials of dabigatran because of the reported experience with ximelagatran, an oral direct thrombin inhibitor associated with idiosyncratic hepatotoxicity. ${ }^{91-94}$

In the RE-MODEL, RE-NOVATE I and II, and RE-MOBILIZE trials, the incidence of liver enzyme elevations in patients treated with dabigatran was the same as or lower than that in patients treated with enoxaparin, which is not associated with hepatotoxicity. Liver enzyme elevations were infrequent and returned to baseline values in all patients. ${ }^{43,44,46,47}$ In the longer term, liver function tests from the RE-LY trial demonstrated that elevation of levels of serum aspartate aminotransferase or alanine aminotransferase to more than three times the upper limit of the normal range did not occur more frequently with either dose of dabigatran $(2.1 \%$ and $1.9 \%)$ than with dose-adjusted warfarin $(2.2 \%) .{ }^{81}$ Similarly, results from the RE-COVER trial showed no evidence of hepatotoxicity associated with dabigatran treatment. ${ }^{73}$ These findings from different patient populations treated with dabigatran for a variety of indications and treatment durations suggest that hepatotoxicity is not a class effect with oral direct thrombin inhibitors.

Concern regarding rebound coagulation effects following the cessation of thromboprophylactic agents requires careful investigation in clinical trials. In a pooled analysis of three trials, one adjudicated acute coronary event was reported during 3 months of follow-up after use of dabigatran $220 \mathrm{mg}$ once daily, two events after dabigatran $150 \mathrm{mg}$ once daily, and 7 events after enoxaparin in orthopedic surgery, suggesting no rebound coagulation effect once treatment with 
dabigatran ends. ${ }^{48}$ Acute coronary syndrome rates were also similar between treatments in the RE-COVER trial. ${ }^{73}$

During the RE-LY trial, there was no statistically significant difference in myocardial infarction rates between the dabigatran doses and warfarin, although the rates of myocardial infarction were numerically higher with dabigatran. The overall rates were low $(0.82,0.81$, and $0.64 \%$ per year with dabigatran $110 \mathrm{mg}$ twice daily, dabigatran $150 \mathrm{mg}$ twice daily, and warfarin, respectively). ${ }^{82}$ The incidence observed with warfarin was similar to that reported in the warfarin arms of previous clinical trials (eg, SPORTIF III and V, ACTIVEW). ${ }^{95-97}$ Similarly, the rates of myocardial infarction reported with ximelagatran and aspirin plus clopidogrel in the same studies were comparable with those seen for dabigatran in RE-LY.95-97 The rates with dabigatran were lower than reported for placebo. ${ }^{98}$

\section{Conclusion}

The Phase III trials of dabigatran have generated approximately 25,124 patient-years of experience to demonstrate the efficacy and safety profile of dabigatran for the prevention of venous and arterial thromboembolic disorders across multiple indications. Results from trials in orthopedic surgery show comparable efficacy and similar bleeding rates to enoxaparin, and dabigatran has been used in clinical practice in this indication since April 2008.

Results from the RE-COVER trial show that dabigatran has similar efficacy and significantly lower rates of major or clinically relevant bleeding compared with warfarin in prevention of recurrent events after acute venous thromboembolism. In addition, results from the RE-LY trial demonstrate that dabigatran $150 \mathrm{mg}$ twice daily has superior efficacy, similar rates of major bleeding, and a reduction in intracranial hemorrhage compared with warfarin for the long-term prevention of stroke in patients with atrial fibrillation. In contrast with the currently recommended and widely used oral anticoagulant agent warfarin, dabigatran provides many advantages in this indication, including predictable anticoagulant effects, no food interactions, few drug interactions, and convenient long-term administration without the need for regular anticoagulation monitoring. In conclusion, dabigatran has the potential to improve the prevention and treatment of venous thromboembolism and the management of stroke prevention in patients with atrial fibrillation.

\section{Disclosure}

This work was supported by Boehringer Ingelheim. Writing and editorial assistance was provided by Rebecca Gardner and Christopher Langford of Parexel, which was contracted by Boehringer Ingelheim for these services. The author has been a scientific consultant to AstraZeneca, Bayer, Boehringer Ingelheim, EMEA, Pfizer, Bristol-Myers Squibb, Sanofi-Aventis, Trigen, TransTech, and GlaxoSmithKline. The author has not received any compensation for the academic work allocated to this review.

\section{References}

1. Hawkins D. The role of oral direct thrombin inhibitors in the prophylaxis of venous thromboembolism. Pharmacotherapy. 2004;24 (10 Pt 2):179S-183S.

2. Fitzmaurice DA, Murray E. Thromboprophylaxis for adults in hospital. BMJ. 2007;334(7602):1017-1018.

3. Heit JA, Silverstein MD, Mohr DN, Petterson TM, O'Fallon WM, Melton LJ III. Predictors of survival after deep vein thrombosis and pulmonary embolism: a population-based, cohort study. Arch Intern Med. 1999;159(5):445-453.

4. Torbicki A, Perrier A, Konstantinides S, et al. Guidelines on the diagnosis and management of acute pulmonary embolism: the Task Force for the Diagnosis and Management of Acute Pulmonary Embolism of the European Society of Cardiology (ESC). Eur Heart J. 2008;29(18): 2276-2315.

5. Siragusa S, Beltrametti C, Barone M, Piovella F. Clinical course and incidence of post-thrombophlebitic syndrome after profound asymptomatic deep vein thrombosis. Results of a transverse epidemiologic study. Minerva Cardioangiol. 1997;45(3):57-66. Italian.

6. Wille-Jorgensen P, Jorgensen LN, Crawford M. Asymptomatic postoperative deep vein thrombosis and the development of postthrombotic syndrome. A systematic review and meta-analysis. Thromb Haemost. 2005;93(2):236-241.

7. Prandoni P, Lensing AW, Cogo A, et al. The long-term clinical course of acute deep venous thrombosis. Ann Intern Med. 1996;125(1): $1-7$.

8. Dahl OE, Pedersen T, Kierulf P, et al. Sequential intrapulmonary and systemic activation of coagulation and fibrinolysis during and after total hip replacement surgery. Thromb Res. 1993;70(6):451-458.

9. Dahl OE, Aspelin T, Arnesen $\mathrm{H}$, et al. Increased activation of coagulation and formation of late deep venous thrombosis following discontinuation of thromboprophylaxis after hip replacement surgery. Thromb Res. 1995;80(4):299-306.

10. Quinlan DJ, Eikelboom JW, Dahl OE, Eriksson BI, Sidhu PS, Hirsh J. Association between asymptomatic deep vein thrombosis detected by venography and symptomatic venous thromboembolism in patients undergoing elective hip or knee surgery. JThromb Haemost. 2007;5(7): 1438-1443.

11. Bjørnarå BT, Gudmundsen TE, Dahl $\mathrm{OE}$. Frequency and timing of clinical venous thromboembolism after major joint surgery. $J$ Bone Joint Surg Br. 2006;88(3):386-391.

12. Warwick D, Friedman RJ, Agnelli G, et al. Insufficient duration of venous thromboembolism prophylaxis after total hip or knee replacement when compared with the time course of thromboembolic events: findings from the Global Orthopaedic Registry. $J$ Bone Joint Surg Br. 2007;89(6):799-807.

13. Seagroatt V, Tan HS, Goldacre M, Bulstrode C, Nugent I, Gill L. Elective total hip replacement: incidence, emergency readmission rate, and postoperative mortality. BMJ. 1991;303(6815):1431-1435.

14. Pellegrini VD Jr, Donaldson CT, Farber DC, Lehman EB, Evarts CM. The John Charnley Award: prevention of readmission for venous thromboembolic disease after total hip arthroplasty. Clin Orthop Relat Res. 2005;441:56-62.

15. Pellegrini VD Jr, Donaldson CT, Farber DC, Lehman EB, Evarts CM. The Mark Coventry Award: prevention of readmission for venous thromboembolism after total knee arthroplasty. Clin Orthop Relat Res. 2006;452:21-27. 
16. Lie SA, Pratt N, Ryan P, et al. Duration of the increase in early postoperative mortality after elective hip and knee replacement. J Bone Joint Surg Am. 2010;92(1):58-63.

17. Ostendorf M, Johnell O, Malchau H, Dhert WJ, Schrijvers AJ, Verbout AJ. The epidemiology of total hip replacement in The Netherlands and Sweden: present status and future needs. Acta Orthop Scand. 2002;73(3):282-286.

18. Pedersen AB, Johnsen SP, Overgaard S, Soballe K, Sorensen HT, Lucht U. Total hip arthroplasty in Denmark: incidence of primary operations and revisions during 1996-2002 and estimated future demands. Acta Orthop. 2005;76(2):182-189.

19. Kurtz S, Mowat F, Ong K, Chan N, Lau E, Halpern M. Prevalence of primary and revision total hip and knee arthroplasty in the United States from 1990 through 2002. J Bone Joint Surg Am. 2005;87(7): 1487-1497.

20. Schulman S, Lindmarker P, Holmstrom M, et al. Post-thrombotic syndrome, recurrence, and death 10 years after the first episode of venous thromboembolism treated with warfarin for 6 weeks or 6 months. J Thromb Haemost. 2006;4(4):734-742.

21. Wolf PA, Abbott RD, Kannel WB. Atrial fibrillation as an independent risk factor for stroke: the Framingham Study. Stroke. 1991;22(8): 983-988.

22. Go AS, Hylek EM, Phillips KA, et al. Prevalence of diagnosed atrial fibrillation in adults: national implications for rhythm management and stroke prevention: the AnTicoagulation and Risk Factors in Atrial Fibrillation (ATRIA) Study. JAMA. 2001;285(18):2370-2375.

23. Fuster V, Ryden LE, Cannom DS, et al. ACC/AHA/ESC 2006 Guidelines for the Management of Patients with Atrial Fibrillation: a report of the American College of Cardiology/American Heart Association Task Force on Practice Guidelines and the European Society of Cardiology Committee for Practice Guidelines (Writing Committee to Revise the 2001 Guidelines for the Management of Patients With Atrial Fibrillation): developed in collaboration with the European Heart Rhythm Association and the Heart Rhythm Society. Circulation. 2006;114(7):e257-e354.

24. Kannel WB, Benjamin EJ. Status of the epidemiology of atrial fibrillation. Med Clin North Am. 2008;92(1):17-40, ix.

25. Dulli DA, Stanko H, Levine RL. Atrial fibrillation is associated with severe acute ischemic stroke. Neuroepidemiology. 2003;22(2): 118-123.

26. Lin HJ, Wolf PA, Kelly-Hayes M, et al. Stroke severity in atrial fibrillation. The Framingham Study. Stroke. 1996;27(10):1760-1764.

27. Becker RC. Thrombogenesis in atrial fibrillation contributing mechanisms and natural history. J Thromb Thrombolysis. 2009;27(1): 119-121.

28. Watson T, Shantsila E, Lip GY. Mechanisms of thrombogenesis in atrial fibrillation: Virchow's triad revisited. Lancet. 2009;373(9658): $155-166$.

29. Choudhury A, Lip GY. Atrial fibrillation and the hypercoagulable state: from basic science to clinical practice. Pathophysiol Haemost Thromb. 2003;33(5-6):282-289.

30. Singer DE, Albers GW, Dalen JE, et al. Antithrombotic therapy in atrial fibrillation: American College of Chest Physicians EvidenceBased Clinical Practice Guidelines (8th Edition). Chest. 2008; 133(6 Suppl):546S-592S.

31. Benjamin EJ, Wolf PA, D'Agostino RB, Silbershatz H, Kannel WB, Levy D. Impact of atrial fibrillation on the risk of death: the Framingham Heart Study. Circulation. 1998;98(10):946-952.

32. Wang TJ, Larson MG, Levy D, et al. Temporal relations of atrial fibrillation and congestive heart failure and their joint influence on mortality: the Framingham Heart Study. Circulation. 2003;107(23):2920-2925.

33. Stewart S, Hart CL, Hole DJ, McMurray JJ. A population-based study of the long-term risks associated with atrial fibrillation: 20 -year follow-up of the Renfrew/Paisley study. Am J Med. 2002;113(5):359-364.

34. Ott A, Breteler MM, de Bruyne MC, van Harskamp F, Grobbee DE, Hofman A. Atrial fibrillation and dementia in a population-based study. The Rotterdam Study. Stroke. 1997;28(2):316-321.
35. Ansell J, Hirsh J, Hylek E, Jacobson A, Crowther M, Palareti G. Pharmacology and management of the vitamin K antagonists: American College of Chest Physicians Evidence-Based Clinical Practice Guidelines (8th Edition). Chest. 2008;133(6 Suppl):160S-198S.

36. Hylek EM, Skates SJ, Sheehan MA, Singer DE. An analysis of the lowest effective intensity of prophylactic anticoagulation for patients with nonrheumatic atrial fibrillation. N Engl J Med. 1996;335(8):540-546.

37. Hauel NH, Nar H, Priepke H, Ries U, Stassen JM, Wienen W. Structurebased design of novel potent nonpeptide thrombin inhibitors. J Med Chem. 2002;45(9):1757-1766.

38. Wienen W, Stassen JM, Priepke H, Ries UJ, Hauel N. In-vitro profile and ex-vivo anticoagulant activity of the direct thrombin inhibitor dabigatran and its orally active prodrug, dabigatran etexilate. Thromb Haemost. 2007;98(1):155-162.

39. Dahl OE. Dabigatran etexilate: an oral direct thrombin inhibitor. Therapy. 2008;5(5):685-695.

40. Stangier J, Eriksson BI, Dahl OE, et al. Pharmacokinetic profile of the oral direct thrombin inhibitor dabigatran etexilate in healthy volunteers and patients undergoing total hip replacement. J Clin Pharmacol. 2005;45(5):555-563.

41. Troconiz IF, Tillmann C, Liesenfeld KH, Schafer HG, Stangier J. Population pharmacokinetic analysis of the new oral thrombin inhibitor dabigatran etexilate (BIBR 1048) in patients undergoing primary elective total hip replacement surgery. J Clin Pharmacol. 2007;47(3): 371-382.

42. Geerts WH, Bergqvist D, Pineo GF, et al. Prevention of venous thromboembolism: American College of Chest Physicians evidence-based clinical practice guidelines (8th Edition). Chest. 2008;133(6 Suppl): 381S-453S.

43. Eriksson BI, Dahl OE, Rosencher N, et al. Dabigatran etexilate versus enoxaparin for prevention of venous thromboembolism after total hip replacement: a randomised, double-blind, non-inferiority trial. Lancet. 2007;370(9591):949-956.

44. Eriksson BI, Dahl OE, Rosencher N, et al. Oral dabigatran etexilate vs subcutaneous enoxaparin for the prevention of venous thromboembolism after total knee replacement: the RE-MODEL randomized trial. J Thromb Haemost. 2007;5(11):2178-2185.

45. Pradaxa. Summary of product characteristics. Ingelheim am Rhein, Germany: Boehringer Ingelheim International GmbH; 2011. Available from: http://www.medicines.org.uk/EMC/medicine/24839/SPC/ Pradaxa+150+mg+hard+capsules/. Accessed November 2, 2011.

46. Eriksson BI, Dahl OE, Huo MH, et al. Oral dabigatran versus enoxaparin for thromboprophylaxis after primary total hip arthroplasty (RE-NOVATE II*). A randomised, double-blind, non-inferiority trial. Thromb Haemost. 2011;105(4):721-729.

47. Ginsberg JS, Davidson BL, Comp PC, et al. Oral thrombin inhibitor dabigatran etexilate vs North American enoxaparin regimen for prevention of venous thromboembolism after knee arthroplasty surgery. J Arthroplasty. 2009;24(1):1-9.

48. Friedman RJ, Dahl OE, Rosencher N, et al. Dabigatran versus enoxaparin for prevention of venous thromboembolism after hip or knee arthroplasty: a pooled analysis of three trials. Thromb Res. 2010;126(3): 175-182.

49. Dahl OE, Kurth AA, Rosencher N, et al. Dabigatran etexilate $150 \mathrm{mg}$ once daily for the prevention of venous thromboembolism after total knee or hip replacement surgery in the elderly and those with moderate renal impairment. J Thromb Haemost. 2009;(7 Suppl 2):PP-WE-205.

50. European Medicines Agency. European public assessment report 2011: Pradaxa. Available from: http:/www.emea.europa.eu/humandocs/ Humans/EPAR/pradaxa/pradaxa.htm. Accessed November 2, 2011.

51. Arixtra. Summary of product characteristics. Middlesex, UK: Glaxo Group Ltd; 2011.

52. Turpie AG, Lassen MR, Davidson BL, et al. Rivaroxaban versus enoxaparin for thromboprophylaxis after total knee arthroplasty (RECORD4): a randomised trial. Lancet. 2009;373(9676):1673-1680.

53. Eriksson BI, Borris LC, Friedman RJ, et al. Rivaroxaban versus enoxaparin for thromboprophylaxis after hip arthroplasty. $N$ Engl J Med. 2008;358(26):2765-2775. 
54. Kakkar AK, Brenner B, Dahl OE, et al. Extended duration rivaroxaban versus short-term enoxaparin for the prevention of venous thromboembolism after total hip arthroplasty: a double-blind, randomised controlled trial. Lancet. 2008;372(9632):31-39.

55. Lassen MR, Ageno W, Borris LC, et al. Rivaroxaban versus enoxaparin for thromboprophylaxis after total knee arthroplasty. $N$ Engl J Med. 2008;358(26):2776-2786

56. FDA Cardiovascular and Renal Drugs Advisory Committee Meeting. Available from: http://www.fda.gov/downloads/AdvisoryCommittees/ CommitteesMeetingMaterials/Drugs/CardiovascularandRenalDrugs AdvisoryCommittee/UCM143660.pdf. Accessed March 2, 2010.

57. Gómez-Outes A, Suárez-Gea ML, Blázquez-Pérez A, Pozo-Hernández C, Vargas-Castrillón E. Will oral rivaroxaban improve clinically relevant outcomes and thromboprophylaxis management in the orthopedic patient? J Thromb Haemost. 2009;7(12): 2149-2150.

58. Huisman MV, Quinlan DJ, Dahl OE, Schulman S. Enoxaparin versus dabigatran or rivaroxaban for thromboprophylaxis after hip or knee arthroplasty: results of separate pooled analyses of phase III multicenter randomized trials. Circ Cardiovasc Qual Outcomes. 2010;3(6): $652-660$.

59. Jensen CD, Steval A, Partington PF, Reed MR, Muller SD. Return to theatre following total hip and knee replacement, before and after the introduction of rivaroxaban: a retrospective cohort study. J Bone Joint Surg Br. 2011;93(1):91-95.

60. Trkulja V, Kolundzic R. Rivaroxaban vs dabigatran for thromboprophylaxis after joint-replacement surgery: exploratory indirect comparison based on meta-analysis of pivotal clinical trials. Croat Med J. 2010;51(2):113-123.

61. Turpie AG, Benson A, Misselwitz F. Author reply. Lancet. 2009;374: 683.

62. Van Thiel D, Kalodiki E, Wahi R, Litinas E, Haque W, Rao G. Interpretation of benefit-risk of enoxaparin as comparator in the RECORD program: rivaroxaban oral tablets (10 milligrams) for use in prophylaxis in deep vein thrombosis and pulmonary embolism in patients undergoing hip or knee replacement surgery. Clin Appl Thromb Hemost. 2009;15(4):389-394.

63. Turpie AG, Lassen MR, Eriksson BI, et al. Rivaroxaban for the prevention of venous thromboembolism after hip or knee arthroplasty. Pooled analysis of four studies. Thromb Haemost. 2011;105(3): 444-453.

64. Gómez-Outes A, Suárez-Gea ML, Blázquez-Pérez A, PozoHernández C, Vargas-Castrillón E. Rivaroxaban versus enoxaparin after total knee arthroplasty. Lancet. 2009;374(9691):682.

65. Food and Drug Administration. Xarelto approval letter. Available from: http:// www.accessdata.fda.gov/drugsatfda_docs/appletter/2011/022406s000ltr.pdf. Accessed November 2, 2011.

66. Lassen MR, Raskob GE, Gallus A, Pineo G, Chen D, Hornick P. Apixaban versus enoxaparin for thromboprophylaxis after knee replacement (ADVANCE-2): a randomised double-blind trial. Lancet. 2010; 375(9717):807-815.

67. Lassen MR, Gallus A, Raskob GE, Pineo G, Chen D, Ramirez LM. Apixaban versus enoxaparin for thromboprophylaxis after hip replacement. N Engl J Med. 2010;363(26):2487-2498.

68. Lassen MR, Raskob GE, Gallus A, Pineo G, Chen D, Portman RJ. Apixaban or enoxaparin for thromboprophylaxis after knee replacement. N Engl J Med. 2009;361(6):594-604.

69. Dahl OE, Borris LC, Bergqvist D, et al. Major joint replacement. A model for antithrombotic drug development: from proof-of-concept to clinical use. Int Angiol. 2008;27(1):60-67.

70. Dahl OE, Quinlan DJ, Bergqvist D, Eikelboom JW. A critical appraisal of bleeding events reported in venous thromboembolism prevention trials of patients undergoing hip and knee arthroplasty. $J$ Thromb Haemost. 2010;8(9):1966-1975.

71. Huisman MV, Bounameaux H. Treating patients with venous thromboembolism: initial strategies and long-term secondary prevention. Semin Vasc Med. 2005;5(3):276-284.
72. Kearon C, Kahn SR, Agnelli G, Goldhaber S, Raskob GE, Comerota AJ. Antithrombotic therapy for venous thromboembolic disease: American College of Chest physicians evidence-based clinical practice guidelines (8th Edition). Chest. 2008;133(6 Suppl):454S-545S.

73. Schulman S, Kearon C, Kakkar AK, et al. Dabigatran versus warfarin in the treatment of acute venous thromboembolism. $N$ Engl J Med. 2009;361(24):2342-2352.

74. Fiessinger JN, Huisman MV, Davidson BL, et al. Ximelagatran vs low-molecular-weight heparin and warfarin for the treatment of deep vein thrombosis: a randomized trial. JAMA. 2005;293(6): 681-689.

75. Secondary prevention of venous thrombo embolism [NCT00329238]. [ClinicalTrials.gov]. Available from: http://clinicaltrials.gov/ct2/show/ NCT00329238?term=dabigaran\&rank=17. Accessed August 4, 2011.

76. Twice-daily oral direct thrombin inhibitor dabigatran etexilate in the long term prevention of recurrent symptomatic venous thromboembolism [NCT00558259]. [ClinicalTrials.gov]. Available from: http://clinicaltrials. gov/ct $2 /$ show/NCT000558259?term=dabigatran\&rank=1. Accessed August 4, 2011.

77. Bauersachs R, Berkowitz SD, Brenner B, et al. Oral rivaroxaban for symptomatic venous thromboembolism. N Engl J Med. 2010;363(26): 2499-2510.

78. Cairns JA, Connolly S, McMurtry S, Stephenson M, Talajic M. Canadian Cardiovascular Society atrial fibrillation guidelines 2010: prevention of stroke and systemic thromboembolism in atrial fibrillation and flutter. Can J Cardiol. 2011;27(1):74-90.

79. Camm AJ, Kirchhof P, Lip GY, et al. Guidelines for the management of atrial fibrillation: the Task Force for the Management of Atrial Fibrillation of the European Society of Cardiology (ESC). Eur Heart J. 2010;31(19):2369-2429.

80. Wann LS, Curtis AB, Ellenbogen KA, et al. 2011 ACCF/AHA/HRS focused update on the management of patients with atrial fibrillation (update on dabigatran): a report of the American College of Cardiology Foundation/American Heart Association Task Force on practice guidelines. Circulation. 2011;123(10):1144-1150.

81. Connolly SJ, Ezekowitz MD, Yusuf S, et al. Dabigatran versus warfarin in patients with atrial fibrillation. $N$ Engl $J$ Med. 2009;361(12): 1139-1151.

82. Connolly SJ, Ezekowitz MD, Yusuf S, Reilly PA, Wallentin L. Newly identified events in the RE-LY trial. $N$ Engl J Med. 2010;363(19): 1875-1876.

83. Ezekowitz MD, Wallentin L, Connolly SJ, et al. Dabigatran and warfarin in vitamin $\mathrm{K}$ antagonist-naive and -experienced cohorts with atrial fibrillation. Circulation. 2010;122(22):2246-2253.

84. Diener HC, Connolly SJ, Ezekowitz MD, et al. Dabigatran compared with warfarin in patients with atrial fibrillation and previous transient ischaemic attack or stroke: a subgroup analysis of the RE-LY trial. Lancet Neurol. 2010;9(12):1157-1163.

85. Gage BF. Can we rely on RE-LY? N Engl J Med. 2009;361(12): 1200-1202.

86. Pradaxa. Prescribing information. Ridgefield, CT: Boehringer Ingelheim Pharmaceuticals Inc; 2011. Available from: http:// bidocs.boehringer-ingelheim.com/BIWebAccess/ViewServlet. ser?docBase=renetnt\&folderPath=/Prescribing\%20Information/PIs/ Pradaxa/Pradaxa.pdf. Accessed November 2, 2011.

87. Product Monograph. Pradax dabigatran etexilate capsules. [Boehringer Ingelheim Canada website]. Available from: http://www.boehringeringelheim.ca/content/dam/internet/opu/ca_EN/documents/humanhealth/ product_monograph/Pradax-pm.pdf. Accessed January 25, 2011.

88. Patel MR, Mahaffey KW, Garg J, et al. Rivaroxaban versus warfarin in nonvalvular atrial fibrillation. $N$ Engl J Med. 2011;365(10): 883-891.

89. Connolly SJ, Eikelboom J, Joyner C, et al. Apixaban in patients with atrial fibrillation. N Engl J Med. 2011;364(9):806-817.

90. Granger CB, Alexander JH, McMurray JJ, et al. Apixaban versus warfarin in patients with atrial fibrillation. $N$ Engl J Med. 2011;365(11): 981-992. 
91. Agnelli G, Eriksson BI, Cohen AT, et al. Safety assessment of new antithrombotic agents: lessons from the EXTEND study on ximelagatran. Thromb Res. 2009;123(3):488-497.

92. Eriksson BI, Dahl OE, Ahnfelt L, et al. Dose escalating safety study of a new oral direct thrombin inhibitor, dabigatran etexilate, in patients undergoing total hip replacement: BISTRO I. J Thromb Haemost. 2004;2(9):1573-1580.

93. Eriksson BI, Dahl OE, Buller HR, et al. A new oral direct thrombin inhibitor, dabigatran etexilate, compared with enoxaparin for prevention of thromboembolic events following total hip or knee replacement: the BISTRO II randomized trial. J Thromb Haemost. 2005;3(1):103-111.

94. Testa L, Bhindi R, Agostoni P, Abbate A, Zoccai GG, van Gaal WJ. The direct thrombin inhibitor ximelagatran/melagatran: a systematic review on clinical applications and an evidence based assessment of risk benefit profile. Expert Opin Drug Saf. 2007;6(4):397-406.
95. Connolly S, Pogue J, Hart R, et al. Clopidogrel plus aspirin versus oral anticoagulation for atrial fibrillation in the Atrial fibrillation Clopidogrel Trial with Irbesartan for prevention of Vascular Events (ACTIVE W): a randomised controlled trial. Lancet. 2006;367(9526):1903-1912.

96. Olsson SB. Stroke prevention with the oral direct thrombin inhibitor ximelagatran compared with warfarin in patients with non-valvular atrial fibrillation (SPORTIF III): randomised controlled trial. Lancet. 2003;362(9397):1691-1698.

97. Albers GW, Diener HC, Frison L, et al. Ximelagatran vs warfarin for stroke prevention in patients with nonvalvular atrial fibrillation: a randomized trial. JAMA. 2005;293(6):690-698.

98. Preliminary report of the Stroke Prevention in Atrial Fibrillation Study. N Engl J Med. 1990;322(12):863-868.
Vascular Health and Risk Management

\section{Publish your work in this journal}

Vascular Health and Risk Management is an international, peerreviewed journal of therapeutics and risk management, focusing on concise rapid reporting of clinical studies on the processes involved in the maintenance of vascular health; the monitoring, prevention and treatment of vascular disease and its sequelae; and the involvement of

\section{Dovepress}

metabolic disorders, particularly diabetes. This journal is indexed on PubMed Central and MedLine. The manuscript management system is completely online and includes a very quick and fair peer-review system, which is all easy to use. Visit http://www.dovepress.com/ testimonials.php to read real quotes from published authors. 